\title{
Editorial
}

\section{Style rotation and dynamic asset allocation}

Journal of Asset Management (2011) 12, 377. doi:10.1057/jam.2011.33

This is one of two special issues that we are pleased to publish in the Journal of Asset Management, the other being on regime switching. The articles in this issue all address, in a broad context, different aspects of style rotation. By this, I mean that an asset allocation between different styles is unlikely to be optimal if the proportions are constant through time. Some of the articles address this directly, for example, De Moerloose and Giot. They look at the Fama-French data and build logit models to choose between value and growth as opposed to buy-and-hold strategies or momentum strategies. A more indirect evaluation of the merits of value versus growth styles is the work by Wang, who looks at the impact of time horizon on their risks and returns. I will not detail the contributions of the other authors, except to say that they all contribute something insightful to this topic.

It is worth speculating as to why style rotation may or may not be desirable.

Behavioural economics sometimes argues that there are returns to momentum, say, as a consequence of the human condition. Thus, human inadequacies, such as hanging on too long to things that have done well in the past, or whatever, induce autocorrelation in traded returns, which smart investors can profit from. Presumably, the smart investors have undergone courses in financial psychotherapy, and have managed to break the adamantine chains that the other minds are bound by. The trouble I have with this argument is that, if true, it is hard to see why this human frailty should change much through time. Because it is unlikely to change, there seems to be little argument in favour of moving from one style to another. A more plausible structure is that the market is made up of agents of different kinds; that their strategies will vary between behavioural and rational, and that different macro-economic conditions will favour one group relative to another in terms of effectively front-running each other. Finally, of course, it may be possible to capture some of these group linkages. An article in this issue that addresses some of these issues is the one by Anheluk and Simlai, which looks at spillovers between market capitalisation portfolios and book to market ones.

Stephen Satchell

Editor

E-mail: ses999gb@yahoo.co.uk 